\title{
Outcrossing rates as related to plant density in Phlox drummondii
}

\author{
Lee Watkins and \\ Donald A. Levin
}

\author{
Department of Botany, University of Texas, Austin, \\ Texas 78713, U.S.A.
}

Outcrossing rates were investigated in 20 populations of Phlox drummondii using polymorphic allozyme loci. The analysis of progeny genotype arrays gave outcrossing estimates which varied from $t=0.69$ to 1.01 ; the mean was 0.86 . The estimated outcrossing rate deviated significantly from random mating in 13 populations. The deviation was due principally to crossing among relatives. Outcrossing rates were a weak inverse function of density. At one site the density of some subpopulations was artifically reduced; and the outcrossing rates in these subpopulations were significantly greater than in adjacent unmanipulated subpopulations.

\section{INTRODUCTION}

Because seeds are usually dispersed within a few canopy diameters of their maternal parent (Levin and Kerster, 1974; Levin, 1981), related plants tend to be near each other rather than being randomly distributed. Since crosses in nature tend to be among nearby plants (Levin and Kerster, 1974; Handel, 1983), inbreeding is likely to ensue even if plants are self-incompatible.

The mating structure of animal-pollinated plant populations homogenizes gene pools more when the density of conspecific plants is low than when it is high, because pollinators move greater distances between plants (Levin and Kerster, 1974; Handel, 1983). Accordingly, the relatedness of neighbouring plants is likely to be higher in high density populations than those of low density, all else being equal. Given that crosses tend to be among neighbouring plants (Levin and Kerster, 1974), it follows that the level of random outcrossing is likely to be negatively correlated with density, because the higher the incidence of crossing between relatives the lower is the level of random outcrossing.

The purpose of this study was to test the hypothesis that the level of random outcrossing is an inverse function of plant density within the between populations. The study organism was Phlox drummondii. In this species, plant related- ness tends to decline as the distance between plants increases, as indicated by positive correlations between interplant distance and (i) the viability of developing seeds (Levin, 1984) and (ii) pollenpistil compatibility (Levin, 1989).

\section{METHODS}

\section{Study organism}

Phlox drummondii Hook, is one of the most conspicuous elements of the spring flora of central Texas, where it commonly forms discrete populations of dozens to several thousands of individuals along roadsides and in fields. The species flowers from March until June.

Phlox drummondii is self-incompatible and is pollinated by a variety of lepidopterans, including Battus philenor and other large swallowtails (Papilionidae), hawkmoths (Sphingidae), skippers (Hesperidae), and sulphurs (Pieridae). There are three ovules per flower, which typically yield $c a$. $2 \cdot 25$ seeds per capsule. Pollen and seeds tend to be distributed narrowly in space (Levin, 1981, 1983). The species is weakly self-fertile in the greenhouse (Levin, 1985), and pollinations with mixtures of cross and self pollen $(1: 1)$ yield almost exclusively cross progeny. Thus the species has a strong penchant for outbreeding. 


\section{Geographical survey}

In the spring of 1983 twenty populations were sampled across the geographic range of the species. The locations, which are given in table 1 , are all in Texas. Between 25 and 30 plants were sampled at about $1 \mathrm{~m}$ intervals along a $35 \mathrm{~m}$ linear transect in each population, with as many seeds as possible being collected from each maternal plant for electrophoretic analysis. The density of flowering plants in each population was estimated from a one square metre quadrat placed at five points along the transect.

\section{Density manipulation experiment}

The study population was located on the Charles Sommers Ranch, $1.5 \mathrm{~km}$ south of Elgin, Bastrop County, Texas. The study site consisted of an approximately $0 \cdot 1$ hectare section of a permanent pasture, characterized by the sandy soil and gopher disturbance typical of Phlox sites. It is subject to occasional grazing, but is otherwise protected from disturbance. The site has existed in its present state for at least 50 years.

In March of 1985 a portion of the study area was divided into six quadrats $(2 \times 3)$ of four metres on each side, which were then subdivided into sixteen one square metre plots. Alternate quadrats were either thinned to two plants per square metre or left unmanipulated, creating a checkerboard design. Two plants per square metre corresponds to the lowest density found in the geographic survey, which would be about the minimal density for non-ephemeral Phlox populations. Flower plant density varied from 10 to 36 plants per square metre $($ means $=23 \cdot 2, \mathrm{sd}=7 \cdot 32)$. Initial density was not significantly different between quadrats (ANOVA $F=0.54, P=0.75$ ). The six quadrats were several metres apart, and the vegetation between them was unaltered.

From early May, seeds were collected twice a week from one plant in each of the thinned plots and from a designated plant in the centre of each of the unmanipulated plots. Seed collection continued until the plants senesced in early June.

\section{Electrophoresis}

Seedlings were crushed in a $3 \mathrm{ml}$ disposable plastic beaker in three drops of extraction buffer (Heywood, 1980). The homogenate was then absorbed onto $2 \times 4 \mathrm{~mm}$ paper wicks and subjected to horizontal starch gel electrophoresis. Four enzyme

Table 1 Adult and pollen allele frequencies for polymorphic loci in Phlox populations

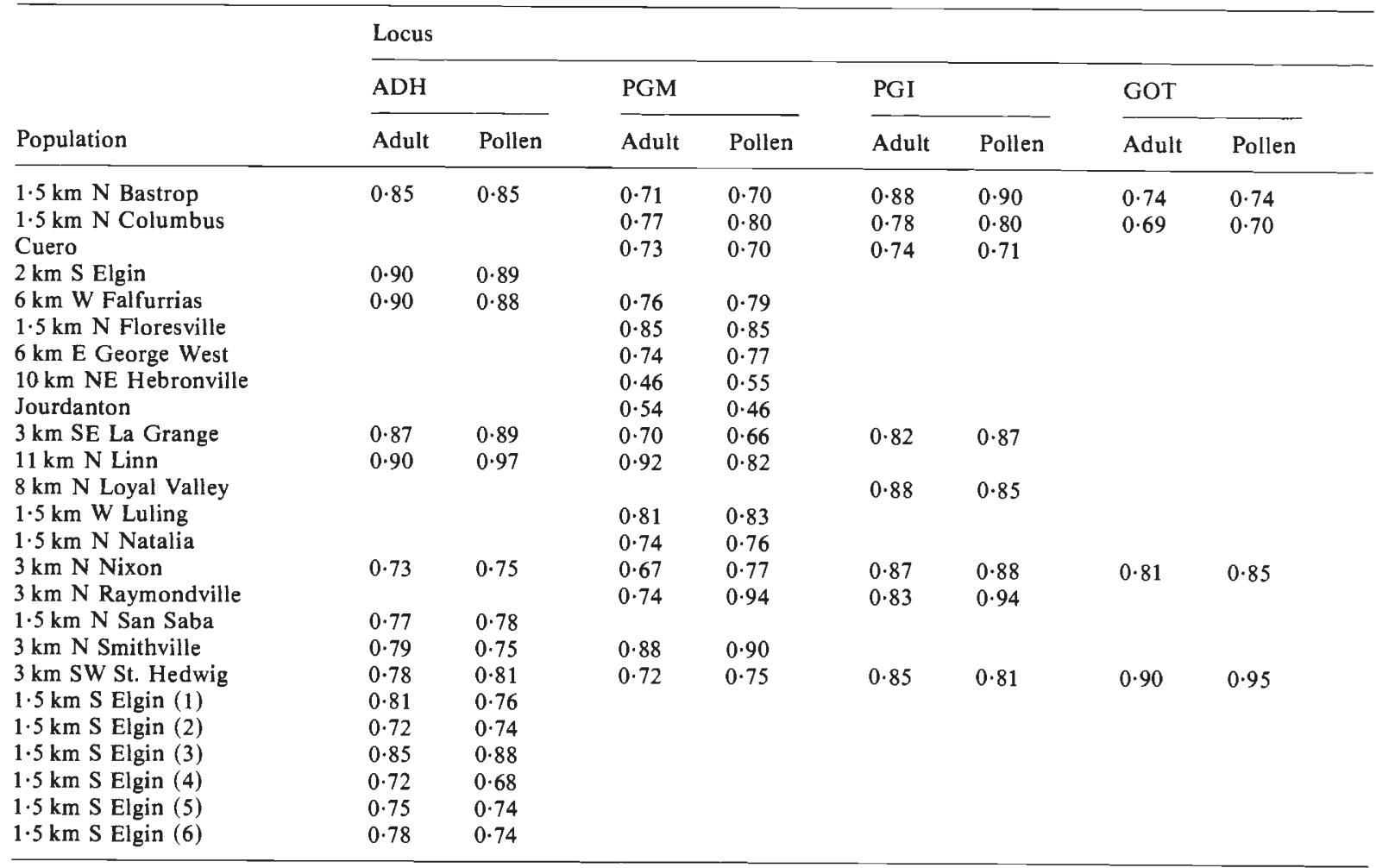


loci known to be polymorphic in $P$. drummondii were chosen for analysis: alcohol dehydrogenase $(A D H)$, glutamate oxaloacetate transaminase (GOT-2), phosphoglucose isomerase (PGI-2), and phosphoglucomutase (PGM-2). Designations for loci and alleles follow Levin (1978). The mode of inheritance of polymorphoric enzyme loci in $P$. drummondii was established by Levin (1978). Two types of buffer systems were used. The enzymes run on each system and the staining references are: (1) $\mathrm{LiOH}$ discontinuous buffer, gel modified to $p \mathrm{H} 8 \cdot 5$, electrode modified to $p \mathrm{H} 7 \cdot 8, P G I$ and GOT (Leverich, 1977), ADH and PGM (Heywood, 1980); (2) Tris-EDTA-Borate continuous buffer, $A D H$ and PGM (Heywood, 1980).

Twelve progeny were examined for most families. The minimum number of progeny per family was eight.

\section{Outcrossing estimation}

The frequency of alleles in the pollen pool and the level of outcrossing $(t)$ were estimated by the method of Clegg et al. (1978). From an initial estimate of pollen pool frequencies and the rate of outcrossing, this method infers the maternal genotype for each progeny array. It then estimates jointly the pollen allele frequencies and rate of outcrossing with a maximum likelihood procedure. The new estimates of pollen allele frequencies and outcrossing rates are once again used to infer maternal genotypes. This process is repeated until the maternal genotypes, pollen allele frequencies and outcrossing rates do not change with further iteration. Estimates of random outcrossing are based on the mixed-mating model (Fyfe and Bailey, 1951; Shaw et al., 1981) which assumes that (a) each viable offspring results from a random outcross (with probability $t$ ) or a self-fertilization $(s=1-t)$, (b) allele frequencies in the pollen pool are homogeneous among egg parents, (c) the probability of outcrossing is independent of maternal plant genotype, and (d) no selection occurs between fertilization and the census of seed progenies.

Heterogeneity of outcrossing rates between populations and loci, and deviations of outcrossing rates from 1.0 were investigated using the likelihood ratio test (Rao, 1973), calculated as described in Yeh and Morgan (1987). To test whether there was heterogeneity in the pollen pool allele frequencies among maternal plants, the number of heterozygous progeny among homozygous mothers of the same genotype was compared with a likelihood-ratio contingency test, or G-test (Sokal and Rohlf, 1981). When sample sizes permitted,
$G$ values and degrees of freedom for all homozygous genotypes at a locus were pooled. Goodnessof-fit likelihood ratio tests were performed on allele frequencies in the estimated pollen pool to determine if the effective pollen pool was a random sample of the maternal plants.

Equilibrium inbreeding coefficients, $F_{e}=$ $(1-t) /(1+t)$ were calculated for the outcrossing estimates of each locus in each population (Fyfe and Bailey, 1951). These values were compared with Wright's (1951) fixation index $\left(F_{i s}\right) . F_{\text {is }}$ and $F_{e}$ are expected to be equal if all Hardy-Weinberg assumptions are met and if the genotype frequencies are determined only by the mating system (Hedrick, 1983). Departures from random mating were analysed using the methods of Weir and Cockerham (1984), and Workman and Niswander (1970), as implemented in the computer program GENESTATS (Black and Krafsur, 1985). Chisquare statistics are as described therein.

\section{RESULTS}

\section{Geographic Survey}

Three of the populations were variable at four loci, two were variable at three loci, four at two, and eleven populations at one locus. Two alleles were present at each polymorphic locus. Frequencies of the common allele in the maternal plants and in the pollen pool are presented for each population in table 1 . Heterogeneity chi-square tests comparing maternal and estimated pollen pool allele frequencies indicated that in all cases the pollen pool is a random sample of the adult alleles. Evidence to the contrary would violate the assumption of neutrality in the mixed-mating model, and thus introduce another source of variation in the outcrossing estimates (Clegg, 1980).

The estimates of effective outcrossing rate vary considerably across the range of the species. Estimates range from 0.69 to 1.01 , with an overall mean of 0.86 (table 2). Despite the wide range of outcrossing rate estimates, they do form a homogenous set $(G=25 \cdot 35,36 \mathrm{df})$. Similarly, there is no evidence of significant heterogeneity among the estimates for different loci in any of the nine populations with multiple single-locus estimates. The estimated outcrossing rate differs significantly from random mating in 13 populations (table 2).

Outcrossing rates tend to be an inverse function of plant density (fig. 1). The significance of this trend was investigated via linear regression (table 3 ). The overall model is not significant at the 5 per cent level, but it is significant at the 5.4 per cent 
Table 2 Density and estimates of effective outcrossing rate in twenty populations. Standard errors of $t$ are in parentheses

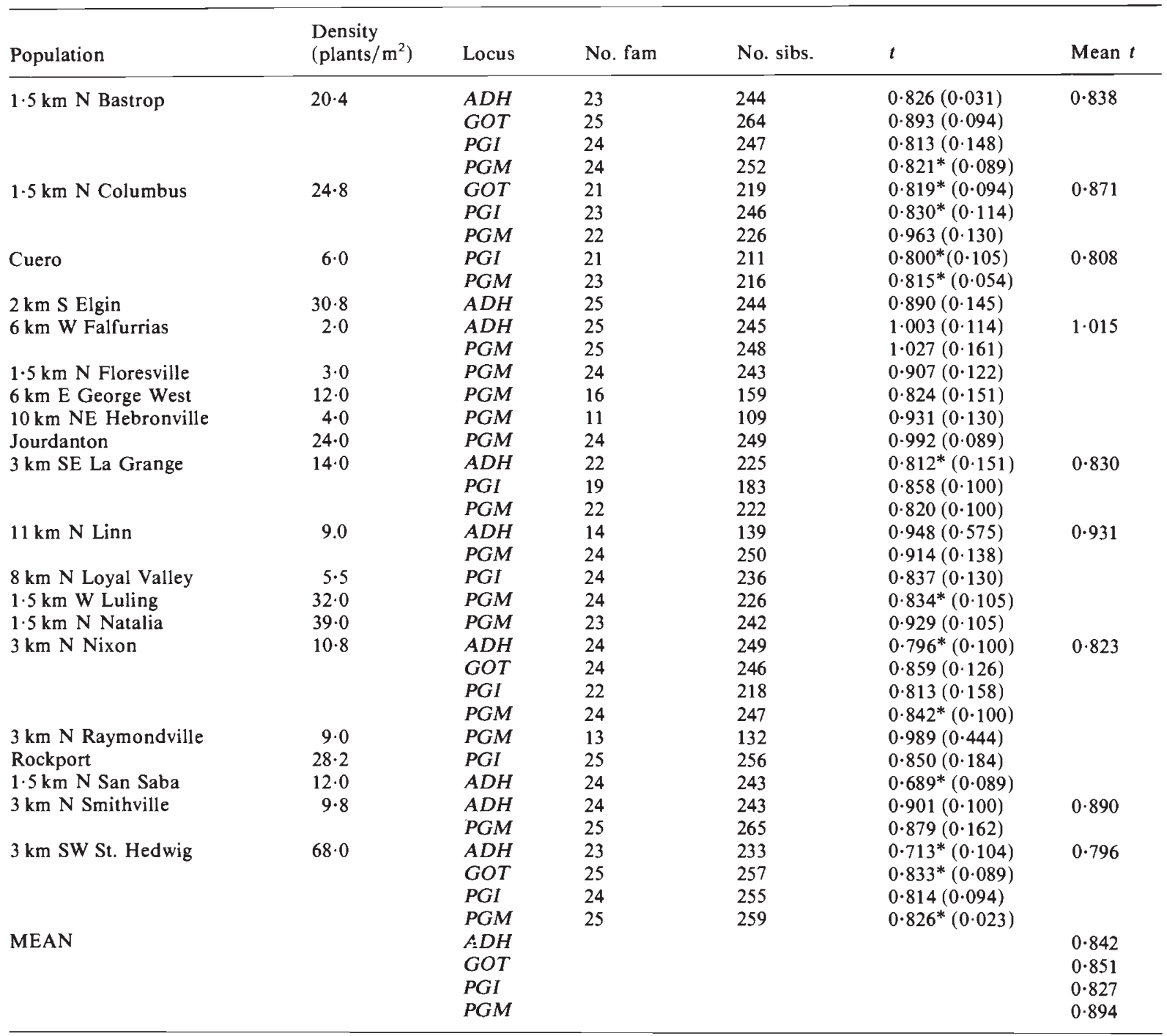

* Significantly different $t=1 \cdot 0(P<0 \cdot 05)$.

level. The plot of density versus outcrossing rate yields a hyperbolic curve (fig. 1).

\section{Inbreeding coefficients}

The genotypic structure of the parental generation in Phlox populations is consistent with moderate inbreeding (table 4). With the exception of Linn and Raymondville in the parental generation, and Falfurrias and Hebronville in the filial, all $F_{\text {is }}$ values are positive, indicating an excess of homozygotes over Hardy-Weinberg expectations. Roughly a third of these deviations are significant, but there is little correspondence between significance in the two generations (table 4). Despite

Table 3 Regression of thirty-seven single locus estimates of outcrossing rate on mean density among twenty populations of $P$. drummondii

\begin{tabular}{lrlll}
\hline Source & df & SS & $F$ & $P$ \\
\hline Model & 1 & 0.0205033 & 3.985 & 0.054 \\
Error & 35 & 0.1800737 & & \\
Pure Error & 18 & 0.0312459 & 5.043 & $<0.010$ \\
Lack-of-Fit & 17 & 0.1488278 & & \\
C Total & 36 & 0.2005771 & & \\
\hline
\end{tabular}




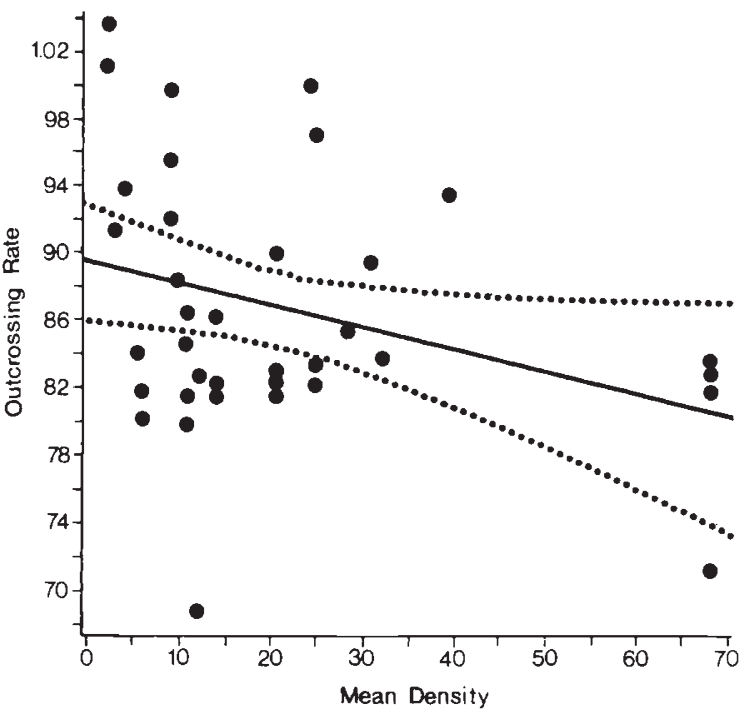

Figure 1 Linear regression of estimated outcrossing rate on mean population density in $P$. drummondii, with 95 per cent confidence limits of mean single-locus estimate for each population.

the differences in the magnitude of the $F_{\text {is }}$ values in the two generations, they are significantly correlated (Spearman $r=0.366, P=0.026$ ).

The adult generation shows a consistently higher proportion of homozygotes than the progeny. The mean $F_{\text {is }}$ value of the adult generation is 0.352 , which is about three times that in the progeny $(0 \cdot 128$; table 4$)$.

A comparison of the progeny fixation index with $\mathrm{F}_{\mathrm{e}}$ indicates that none of the populations deviate significantly from mating system equilibrium. However, the adult fixation index is much greater than $F_{e}$. The overall level of homozygote excess due to the mating system, $F_{e}=0.074$, is approximately what was predicted based on seed and pollen dispersal patterns and proximitydependent seed abortion (Levin, 1984, $F=0 \cdot 10$ ).

\section{Density manipulation experiment}

Density manipulation had a significant effect on outcrossing rates in the experimental plots at Elgin. The outcrossing rates in the unmanipulated plots were $0.882,0.904$, and 0.919 . The mean was 0.902 . In contrast, the outcrossing rates for the thinned plots were $0.998,1.026$, and 1.044 . The mean was 1.019. A $t$-test of the difference between the plots was statistically significant $(t=5 \cdot 42, \mathrm{df}=4)$.

The fixation index in the progeny was less in the thinned subpopulations $(\bar{x}=0.036)$ than the unmanipulated ones $(\bar{x}=0 \cdot 102)$. Such a difference was not apparent in the maternal generation, and indeed none was expected since the genetic structure of that generation was not affected by the thinning treatment (table 5). The fixation indices of the progeny were much closer to the equilibrium inbreeding coefficient than were the indices of the maternal generation. This pattern is like that observed in the other populations.

\section{DISCUSSION}

The level of random outcrossing in $P$. drummondii averages 0.86 , with a range from 0.69 to 1.01 . Values less than 1.0 ostensibly are due almost exclusively to crossing among relatives, because the level of self-compatibility is weak and cross pollen germinates much sooner than self pollen. The rate of outcrossing in Phlox is similar to that in other obligate outbreeders (e.g., Secale cereale, Perez de la Vega and Allard, 1984; Helianthus annuus, Ellstrand et al., 1978; Oenothera organensis, Levin et al., 1979; Clarkia unguiculata, Vasek, 1965; Collinsia heterophylla, Weil and Allard, 1977; Cynosurus cristatus; Ennos, 1985; Fagus sylvatica, Cuguen et al., 1988; Pithcellobium pediculare; O'Malley and Bawa, 1987).

The rate of outcrossing in $P$. drummondii is inversely correlated with density throughout its range, but not significantly so. In the experimental population at Elgin, outcrossing rates were higher in the thinned plots than in the untreated ones. Density-dependent outcrossing is expected, because Phlox pollinators move greater distances as plant density declines, which results in the crossing of more distant and ostensibly less related plants (Levin, 1981). The relationship between outcrossing rates and density was more pronounced among Elgin subpopulations than among populations sampled throughout the species' range. This undoubtedly results from there being less variation in other factors affecting the mating system among the Elgin subpopulations than among the collection of populations.

The relationship between outcrossing and density in wild cross-breeding $P$ drummondii is the converse of that in garden populations of partially self-fertilizing $P$. drummondii cultivars (Levin, unpublished). The deviation from random mating in the cultivar populations is due exclusively to self-fertilization. The greater the distance between plants the lower was the level of pollinator visitation and the greater the level of self-fertilization. These findings are in accord with those of Bateman (1956) on Cheiranthus cheiri. 
Table 4 Observed heterozygosity $\left(\mathrm{H}_{0}\right)$, Wright's fixation index $\left(\mathrm{F}_{\mathrm{is}}\right)$, and equilibrium inbreeding coefficient $\left(\mathrm{F}_{\mathrm{e}}\right)$ for maternal plants and progeny

\begin{tabular}{|c|c|c|c|c|c|c|}
\hline \multirow[b]{2}{*}{ Population } & \multicolumn{3}{|c|}{ Maternal plants } & \multicolumn{3}{|l|}{ Progeny } \\
\hline & Locus & $\mathbf{H}_{0}$ & $\mathrm{~F}_{\text {is }}$ & $\mathrm{F}_{\mathrm{e}}$ & $\mathbf{H}_{0}$ & $\mathrm{~F}_{\text {is }}$ \\
\hline \multirow[t]{4}{*}{$1.5 \mathrm{~km} \mathrm{~N}$ Bastrop } & $A D H$ & $0 \cdot 217$ & $0 \cdot 158$ & 0.095 & $0 \cdot 230$ & 0.088 \\
\hline & $G O T$ & $0.208^{*} \dagger$ & 0.473 & 0.056 & 0.356 & 0.069 \\
\hline & $P G I$ & $0 \cdot 125$ & $0 \cdot 330$ & $0 \cdot 103$ & $0 \cdot 183$ & $0 \cdot 108$ \\
\hline & $P G M$ & $0 \cdot 250$ & 0.395 & 0.098 & $0 \cdot 369^{*}$ & 0.127 \\
\hline \multirow[t]{3}{*}{$1.5 \mathrm{~km} \mathrm{~N}$ Columbus } & $G O T$ & $0.238^{*}$ & 0.443 & 0.099 & $0.352^{*}$ & $0 \cdot 161$ \\
\hline & $P G I$ & $0 \cdot 261$ & 0.233 & 0.093 & $0 \cdot 276^{*}$ & $0 \cdot 193$ \\
\hline & $P G M$ & 0.273 & $0 \cdot 224$ & 0.019 & $0 \cdot 319$ & 0.033 \\
\hline \multirow[t]{2}{*}{ Cuero } & $P G I$ & 0.286 & $0 \cdot 213$ & $0 \cdot 111$ & $0 \cdot 374$ & 0.056 \\
\hline & $P G M$ & $0 \cdot 174^{*} \dagger$ & 0.549 & $0 \cdot 102$ & 0.333 & 0.169 \\
\hline $2 \mathrm{~km} \mathrm{~S}$ Elgin & $A D H$ & $0 \cdot 120$ & 0.333 & 0.058 & $0 \cdot 189$ & 0.042 \\
\hline \multirow[t]{2}{*}{$6 \mathrm{~km} \mathrm{~W}$ Falfurrias } & $A D H$ & $0 \cdot 120$ & 0.333 & -0.014 & -0.208 & -0.013 \\
\hline & $P G M$ & $0 \cdot 200 * \dagger$ & 0.417 & -0.002 & 0.359 & -0.020 \\
\hline $1.5 \mathrm{~km} \mathrm{~N}$ Floresville & $P G M$ & $0 \cdot 125^{*}$ & 0.498 & 0.049 & 0.226 & 0.071 \\
\hline $6 \mathrm{~km} \mathrm{E} \mathrm{George} \mathrm{West}$ & $P G M$ & 0.375 & 0.000 & 0.096 & 0.371 & $0 \cdot 134$ \\
\hline $10 \mathrm{~km}$ NE Hebronville & $P G M$ & $0 \cdot 273$ & 0.436 & $0 \cdot 036$ & 0.505 & -0.012 \\
\hline Jourdanton & $P G M$ & $0 \cdot 333$ & 0.329 & 0.004 & 0.470 & 0.060 \\
\hline \multirow[t]{3}{*}{$3 \mathrm{~km}$ SE La Grange } & $A D H$ & $0 \cdot 182$ & $0 \cdot 228$ & $0 \cdot 104$ & $0 \cdot 187^{*}$ & $0 \cdot 169$ \\
\hline & $P G I$ & $0 \cdot 158^{*}$ & 0.475 & 0.076 & $0.213^{*}$ & $0 \cdot 212$ \\
\hline & $P G M$ & 0.318 & $0 \cdot 236$ & 0.099 & 0.410 & 0.031 \\
\hline \multirow{2}{*}{11 km N Linn } & $A D H$ & $0 \cdot 213$ & $-0 \cdot 120$ & $0 \cdot 027$ & $0 \cdot 112$ & 0.065 \\
\hline & $P G M$ & $0 \cdot 167$ & -0.091 & 0.045 & $0 \cdot 196$ & 0.030 \\
\hline $8 \mathrm{~km} \mathrm{~N}$ Loyal Valley & $P G I$ & $0 \cdot 167$ & 0.238 & 0.089 & $0 \cdot 225$ & $0 \cdot 100$ \\
\hline $1.5 \mathrm{~km} \mathrm{~W}$ Luling & $P G M$ & $0 \cdot 125^{*}$ & 0.590 & 0.090 & 0.239 & 0.225 \\
\hline $1.5 \mathrm{~km} \mathrm{~N}$ Natalia & $P G M$ & 0.261 & 0.324 & 0.037 & $0 \cdot 343$ & 0.095 \\
\hline \multirow[t]{4}{*}{$3 \mathrm{~km} \mathrm{~N} \mathrm{Nixon}$} & $A D H$ & $0 \cdot 292$ & $0 \cdot 262$ & $0 \cdot 114$ & $0.341^{*}$ & $0 \cdot 136$ \\
\hline & $G O$ & $0 \cdot 208$ & $0 \cdot 316$ & 0.076 & $0 \cdot 244^{*}$ & $0 \cdot 139$ \\
\hline & $P G I$ & $0 \cdot 182$ & $0 \cdot 228$ & $0 \cdot 103$ & $0 \cdot 170^{*}$ & $0 \cdot 205$ \\
\hline & $P G M$ & $0 \cdot 250^{*}$ & 0.438 & $0 \cdot 086$ & $0.348 *$ & $0 \cdot 170$ \\
\hline 3 km N Raymondville & $P G M$ & 0.538 & -0.368 & 0.006 & $0 \cdot 250$ & 0.007 \\
\hline Rockport & $P G I$ & $0 \cdot 120$ & 0.333 & 0.081 & $0 \cdot 137^{*}$ & $0 \cdot 147$ \\
\hline $1.5 \mathrm{~km} \mathrm{~N} \mathrm{San} \mathrm{Saba}$ & $A D H$ & $0 \cdot 208^{*}$ & 0.410 & $0 \cdot 184$ & $0 \cdot 251^{*}$ & $0 \cdot 269$ \\
\hline \multirow[t]{2}{*}{3 km N Smithville } & $A D H$ & $0 \cdot 167^{*} \dagger$ & 0.495 & 0.052 & $0 \cdot 309^{*}$ & $0 \cdot 124$ \\
\hline & $P G M$ & $0 \cdot 160$ & $0 \cdot 242$ & 0.064 & 0.185 & 0.065 \\
\hline \multirow[t]{4}{*}{$3 \mathrm{~km}$ SW St. Hedwig } & $A D H$ & $0 \cdot 174^{*}$ & 0.489 & $0 \cdot 168$ & $0.232 *$ & 0.269 \\
\hline & $G O T$ & $0 \cdot 120$ & 0.333 & 0.091 & $0 \cdot 125^{*}$ & $0 \cdot 170$ \\
\hline & $P G I$ & $0 \cdot 208$ & $0 \cdot 164$ & $0 \cdot 103$ & $0 \cdot 251$ & $0 \cdot 105$ \\
\hline & $P G M$ & $0 \cdot 240^{*}$ & 0.405 & 0.096 & $0.332^{*}$ & $0 \cdot 150$ \\
\hline \multirow[t]{4}{*}{ All } & $A D H \ddagger$ & 0.186 & 0.347 & $0 \cdot 086$ & 0.236 & $0 \cdot 148$ \\
\hline & $G O T^{\dagger}$ & $0 \cdot 192$ & 0.423 & 0.081 & 0.267 & $0 \cdot 128$ \\
\hline & $P G I \ddagger$ & $0 \cdot 190$ & 0.294 & 0.095 & $0 \cdot 227$ & $0 \cdot 143$ \\
\hline & $P G M \ddagger$ & 0.236 & $0 \cdot 342$ & 0.056 & 0.316 & 0.094 \\
\hline Mean $\ddagger$ & & $0 \cdot 201$ & 0.352 & $0 \cdot 074$ & $0 \cdot 262$ & $0 \cdot 128$ \\
\hline
\end{tabular}

* Observed genotype frequencies significantly different from expectation under Hardy-Weinberg equilibrium $(P<0 \cdot 05)$.

$\dagger$ Significantly different from expectation under mating system equilibrium.

$¥$ Significant heterogeneity of allele frequencies across populations.

There have been several reports of densitydependent outcrossing. The relationship between density and outcrossing follows that in Phlox, and has to do with the breeding system of the species. There is a negative correlation between plant density and outcrossing rate in the self-incompatible Helianthus annuus (Ellstrand et al., 1978), whereas in self-compatible plants, a decrease in density often is accompanied by a decrease in outcrossing rates (Farris and Mitton, 1984; Dommee et al., 1978; Bateman, 1947, 1956; Fowler, 1964; Marshall and Abbott, 1982; Burdon et al., 1988; Vaquero et al., 1989).

We are aware of only one other comparison of outcrossing rates in adjacent thinned and unmanipulated populations. Neale and Adams (1985) found higher outcrossing rates in thinned Douglas-fir stands, but the differences were not 
Table 5 Observed heterozygosity $\left(\mathrm{H}_{0}\right)$, Wright's fixation index $\left(\mathrm{F}_{\mathrm{is}}\right)$, and equilibrium inbreeding coefficient $\left(F_{e}\right)$ for maternal plants and progeny for density

\begin{tabular}{|c|c|c|c|c|c|}
\hline \multirow[b]{2}{*}{ Population } & \multicolumn{3}{|c|}{ Maternal plants } & \multicolumn{2}{|c|}{ Progeny } \\
\hline & $\mathrm{H}_{0}$ & $F_{\text {is }}$ & $\mathrm{F}_{\mathrm{e}}$ & $\mathrm{H}_{0}$ & $F_{\text {is }}$ \\
\hline \multicolumn{6}{|l|}{ Thinned Treatment } \\
\hline $1.5 \mathrm{~km} \mathrm{~S}$ Elgin 1 & $0 \cdot 250$ & 0.179 & -0.013 & $0 \cdot 349$ & -0.030 \\
\hline $1.5 \mathrm{~km} \mathrm{~S}$ Elgin 2 & 0.313 & 0.227 & 0.021 & $0 \cdot 375$ & 0.039 \\
\hline $1.5 \mathrm{~km} \mathrm{~S}$ Elgin 3 & $0 \cdot 188$ & $0 \cdot 289$ & 0.006 & $0 \cdot 177$ & $0 \cdot 127$ \\
\hline \multicolumn{6}{|l|}{ Thinned } \\
\hline Treatment Mean: & $0 \cdot 250$ & $0 \cdot 259$ & 0.010 & $0 \cdot 300$ & 0.036 \\
\hline \multicolumn{6}{|l|}{ Unmanipulated } \\
\hline \multicolumn{6}{|l|}{ Treatment } \\
\hline $1.5 \mathrm{~km} \mathrm{~S}$ Elgin 4 & $0 \cdot 313$ & $0 \cdot 227$ & 0.062 & 0.375 & 0.092 \\
\hline $1.5 \mathrm{~km} \mathrm{~S}$ Elgin 5 & 0.250 & 0.333 & 0.042 & $0 \cdot 344$ & 0.070 \\
\hline $1.5 \mathrm{~km} \mathrm{~S}$ Elgin 6 & 0.313 & 0.086 & 0.050 & $0 \cdot 307$ & 0.137 \\
\hline \multicolumn{6}{|l|}{ Unmanipulated } \\
\hline Treatment Mean: & $0 \cdot 292$ & $0 \cdot 250$ & 0.052 & $0 \cdot 342$ & $0 \cdot 102$ \\
\hline
\end{tabular}

statistically significant. This species is self-compatible. It is possible that lower levels of consanguineous mating which follow thinning were counterbalanced by higher levels of self-fertilization.

When the outcrossing rate is an inverse function of density, outcrossing rates within populations are probably higher early in the flowering season when there are few individuals in flower than later in the season. Temporal patterns of outcrossing within a season have been studied in Lupinus nanus (Horovitz and Harding, 1972), Echium plantagineum (Burdon et al., 1988) and Pseudotsuga menziesii (El-Kassaby and Ritland, 1986) and Senecio vulgaris (Marshall and Abbott, 1982), all of which are self-compatible but predominantly outcrossing. In all cases outcrossing rates tended to be lower early in the season. This is to be expected in self-compatible species, because widely spaced plants are apt to get less cross pollen than closely spaced plants, be they animal- or wind-pollinated (Levin and Kerster, 1974). Pollinator activity is likely to be a positive function of plant density (Levin and Kerster, 1974; Handel, 1983).

The density of Phlox plants varies from one part of a population to another, and is lower at the periphery. Given the relationship between density and outcrossing, we expect outcrossing rates to be higher in sparse patches and near the periphery than in dense patches. The periphery was not represented in the present study.

The outcrossing rates in $P$. drummondii and in other cross-breeding annuals are not populationspecific constants. Rather, they are expected to change from year to year in accordance with plant density, if populations have genetic substructure. In partial selfers, genetic substructure would not be a prerequisite for density-dependent outcrossing. In perennials, outcrossing rates are expected to change in response to changes in the density of flowering individuals, if populations have genetic substructure or if they are partially self-fertilizing.

In $P$. drummondii the fixation index in the adult population consistently was higher than in the progeny. This is contrary to the norm for crossfertilizing species (Brown, 1979; Yazdani et al., 1985; El-Kassaby et al., 1987; Shea, 1987; Burdon et al., 1988). The only other example of an outcrosser having a higher adult fixation index that we are aware of involves Eucalyptus delegatus (Moran and Brown, 1980). The pattern in Phlox may reflect differences in outcrossing rates between years as has been reported in other species (Moran and Brown, 1980; Cheliak et al., 1985). A lower outcrossing rate would yield a higher fixation index. The pattern also may reflect homozygate advantage. The substantial heterozygote deficiency in $P$. drummondii populations reported here and in an earlier study (Levin, 1977) is much greater than expected even if modest inbreeding is taken into account. Finally, if seeds produced by a given plant are full-sibs rather than half-sibs as is assumed in the mixed-mating model or have a genetic correlation greater than $0 \cdot 25$, the determination of the maternal genotype by likelihood ratio may be biased, and yield a higher fixation index than would otherwise be the case (Schoen and Clegg, 1984, 1986). Our results indicate that the pollen pool used by females was homogeneous. Accordingly the genetic correlation among progeny of single maternal plants is not likely to be 
substantially greater than $0 \cdot 25$. However, it is possible that in the previous generation the genetic correlation among progeny of single seed parents was greater than in the present generation.

In conclusion, density-dependent outcrossing is likely to be the norm in self-incompatible species whose populations have genetic substructure. It also is likely to be the norm in self-compatible species. Density-dependent outcrossing will be most apparent in local areas where other factors affecting the mating system vary little. Interpopulation differences in density undoubtedly explain some of the variation in outcrossing rates among populations which has been reported for many species.

\section{REFERENCES}

BAteman, A. J. 1947. Contamination of seed crops. I. Insect pollination. J. Genet., 48, 257-275.

BATEMAN, A. J. 1956. Cryptic self-incompatibility in the wallflower, Cheiranthus cheiri L. Heredity, 10, 257-261.

BLACK, W. C. AND KRAFSUR, E. S. 1985. A FORTRAN program for analysis of genotypic frequencies and description of the breeding structure of populations. Theor. Appl. Genet., $70,484-490$.

BROWN, A. H. D. 1979. Enzyme polymorphism in plant populations. Theor. Pop. Biol., 15, 1-42.

BURDON, J. J., JAROSZ, A. M. AND BROWN, A. H. D. 1988. Temporal patterns of reproduction and outcrossing in weedy populations of Echium plantagineum. Biol. J. Linn. Soc., 34, 81-92.

CHELIAK, W. M., DANCIK, B. P., MORGAN, K., YEH, F. C. H. AND STROBECK, C. 1985. Temporal variation of the mating system in a natural population of jack pine. Genetics, 109 , 569-584.

CLEGG, M. T. 1980. Measuring plant mating systems. Bioscience, 30, 814-818.

CLEGG, M. T., KAHLER, A. L. AND ALlARD, R. W. 1978. Estimation of life cycle components of selection in an experimental plant population. Genetics, 89, 765-792.

COLES, J. F. AND FOWLER, D. P. 1976. Inbreeding in neighboring trees in two white spruce populations. Silvae Genet., 25 , 29-34.

CUguen, J., MERzeAu, D. AND Thiebaut, B. 1988. Genetic structure of the European beech stands (Fagus sylvatica L.): F-statistics and importance of mating system characteristics in their evolution. Heredity, 60, 91-100.

DOMMEE, B., ASSOUAD, M. W. AND VALDEYRON, G. 1978. Natural selection and gynodioecy in Thymus vulgaris $\mathbf{L}$. Bot. J. Linn. Soc., 77, 17-28.

DRAPER, N. R. AND SMITH, H. 1966. Applied Regression Analysis. John Wiley and Sons, Inc., New York.

EL-KASSABY, Y. A., MEAGHER, M. D., PARKINSON, J. AND PORTLOCK, E. T. 1987. Allozyme inheritance, heterozygosity and outcrossing rate among Pinus monticola near Ladysmith, British Columbia. Heredity, 58, 173-181.

ELLSTRAND, N. C., TORRES, A. M. AND LEVIN, D. A. 1978. Density and the rate of apparent outcrossing in Helianthus annuus (Asteraceae). Syst. Bot. 3, 403-407.
ENNOS, R. A. 1985. The mating system and genetic structure in a perennial grass, Cynosurus cristatus L. Heredity, 55, 121 126.

FARRIS, M. A. AND MITTON, J. B. 1984. Population density, outcrossing rate, and heterozygote superiority in ponderosa pine. Evolution, 38, 1151-1154

FOWLER, D. P. 1964. Effects of inbreeding in red pine, Pinus resinosa Ait. II. Pollination studies. Silvae Genet. 14, 12-23.

FYFE, J. L. AND BAILEY, N. T. J. 1951. Plant breeding studies in leguminous forage crops. I. Natural cross-breeding of winter beans. J. Agric. Sci., 41, 371-378.

HANDEL, S. N. 1983. Pollination ecology, plant population structure, and gene flow. In L. Real (ed.) Pollination Bio logy. Academic Press, New York, pp. 163-211.

HEDRICK, P. W. 1983. Genetics of Populations. Van Nostrand Reinhold, New York.

HEYWOOD, J. S. 1980. Genetic correlates of edaphic differentiation and endemism in Gaillardia. Ph.D. thesis, The University of Texas at Austin.

HOROWITZ, A. AND HARDING, J. 1972. Genetics of Lupinus. V. Intraspecific variability for reproductive traits in Lupinus nanus. Bot. Gaz., 133, 155-166.

LEVERICH, W. J. 1977. A demographic genetic analysis of Phlox drummondii Hook. Ph.D. thesis, The University of Texas at Austin.

LEVIN, D. A. 1977. The organization of genetic variability in Phlox drummondii. Evolution, 31, 477-494.

LEviN, D. A. 1978. Genetic variation in annual Phlox: Selfcompatible versus self-incompatible species. Evolution, 32 , 245-263.

LEVIN, D. A. 1981. Dispersal versus gene flow in plants. Ann. Missouri Bot. Gard., 68, 233-253.

LEVIN, D. A. 1983. An immigration-hybridization episode in Phlox. Evolution, 37, 575-582.

LEVIN, D. A. 1984. Inbreeding depression and proximity dependent crossing success in Phlox drummondii. Evolution, 38 , 166-177.

LEVIN, D. A. 1985. Reproductive character displacement in Phlox. Evolution, 39, 1275-1281.

LEVIN, D. A. 1989. Proximity-dependent cross-compatibility in Phlox. Evolution, 43, 1114-1116.

LEVIN, D. A. AND KERSTER, H. W. 1974. Gene flow in seed plants. Evolutionary Biology, 7, 139-220.

LeVIN, D. A., RITTER, K. AND Ellstrand, N. C. 1979. Protein polymorphism in the narrow endemic Oenothera organensis. Evolution, 33, 534-542.

MARShALL, D. F. AND ABBOTT, R. J. 1982. Polymorphism for outcrossing frequency at the ray floret locus in Senecio vulgaris L. 1. Evidence. Heredity, 48, 227-235.

MORAN, G. B. AND BROWN, A. H. D. 1980. Temporal heterogeneity of outcrossing rates in Alpine Ash (Eucalyptus delegatensis R.T. Bak.). Theor. Appl. Genet., 57, 101-108.

NEALE, D. B. AND ADAMS, w. T. 1985. The mating system in natural and shelterwood stands of Douglas-fir. Theor. Appl. Genet., 71, 201-207.

O'MALLEY, D. M. AND BAWA, K. S. 1987. Mating system of a tropical rain forest tree species. Amer. J. Bot., 74, 11431149.

PEREZ DE LA VEGA, M. AND Allard, R. w. 1984. Mating system and genetic polymorphism in populations of Secale cereale and S. vavilovii. Canad. J. Genet. Cytol., 26, 308-317.

RAO, C. R. 1973. Linear Statistical Inference and its Application, 2nd edn. Wiley and Sons, New York.

SCHOEN, D. J. AND CLEGG, M. T. 1984. Estimation of mating parameters when outcrossing events are correlated. Proc. Natl Acad. Sci. USA, 81, 5258-5262. 
SCHOEN, D. J. AND ClEGG, M. T. 1986. Monte Carlo studies of plant mating system estimation models. The one-pollen parent and mixed mating models. Genetics, 112, 927-945.

SHAW, D. V., KAHLER, A. L. AND ALlARD, R. W. 1981. A multilocus estimator of mating system parameters in plant populations. Proc. Natl Acad. Sci. USA, 78, 1298-1302.

SHEA, K. L. 1987. Effects of population structure and cone production on outcrossing rates in Engelmann spruce and subalpine fir. Evolution, 41, 124-136.

SOKAL, R. R. AND ROHLF, F. J. 1981. Biometry, 2nd edn. Freeman, San Francisco.

VAQUERO, F., VENCES, F. J., GARCIA, P., RAMIREZ, L. AND PEREZ DE AL VEGA, M. 1989. Mating system in rye: variability in relation to the population and plant density. Heredity, 62, 17-26.

VASEK, F. C. 1965. Outcrossing in natural populations. II. Clarkia unguiculata. Evolution, 19, 152-156.

WEIL, J. AND ALLARD, R. W. 1964. The mating system and genetic variability in natural populations of Collinsia heterophylla. Evolution, 18, 515-525.
WEIR, B. S. AND COCKERHAM, C. C. 1984. Estimating F-statistics for the analysis of population structure. Evolution, 38, $1358-1370$.

WOLFF, K., FRISCO, B. AND VAN DAMME, J. M. M. 1988. Outcrossing rates and male sterility in natural populations of Plantago coronopus. Theor. Appl. Genet., 76, 190-196.

Workman, P. L. AND Niswander, J. D. 1970. Population studies on southwest Indian tribes. II. Local genetic differences in the Papago. Amer. J. Human Genet., 22, 24-49.

WRIGHT, S. 1951. The genetical structure of populations. Ann. Eugen., 15, 323-354.

YAZDANI, R., MUONA, O. RUDIN, D. AND SZMIDT, A. E. 1985. Genetic structure of a Pinus sylvestris L. seed-tree stand and naturally regenerated understory. Forest Sci., 31, 430436.

YEH, F. C. AND MORGAN, K. 1987. Mating system and multilocus associations in a natural population of Pseudotsuga menziesii (Mirb.) Franco. Theor. Appl. Genet., 73, 799-808. 